\title{
Effects of 2 weeks lower limb immobilization and two separate rehabilitation regimens on gastrocnemius muscle protein turnover signaling and normalization genes
}

Anders Nedergaard ${ }^{1,2^{*}+}$, Jakob G Jespersen ${ }^{1,2+}$, Jessica Pingel ${ }^{1,2}$, Britt Christensen ${ }^{1,2}$, Nicholas Sroczynski ${ }^{1,2}$, Henning Langberg ${ }^{1,2}$, Michael Kjaer ${ }^{1,2}$ and Peter Schjerling ${ }^{1,2}$

\begin{abstract}
Background: Limb immobilization causes a rapid loss of muscle mass and strength that requires appropriate rehabilitation to ensure restoration of normal function. Whereas the knowledge of muscle mass signaling with immobilization has increased in recent years, the molecular regulation in the rehabilitation of immobilizationinduced muscle atrophy is only sparsely studied. To investigate the phosphorylation and expression of candidate key molecular muscle mass regulators after immobilization and subsequent rehabilitation we performed two separate studies.

Methods: We immobilized the lower limb for 2 weeks followed by the in-house hospital standard physiotherapy rehabilitation (Study 1). Secondly, we conducted an intervention study using the same 2 weeks immobilization protocol during which protein/carbohydrate supplementation was given. This was followed by 6 weeks of rehabilitation in the form of resistance training and continued protein/carbohydrate supplementation (Study 2). We obtained muscle biopsies from the medial gastrocnemius prior to immobilization (PRE), post-immobilization (IMMO) and post-rehabilitation (REHAB) and measured protein expression and phosphorylation of Akt, mTOR, S6k, 4E-BP1, GSK3 $\beta$, ubiquitin and MURF1 and mRNA expression of Atrogin-1, MURF1, FOXO1, 3 and 4 as well as appropriate housekeeping genes.
\end{abstract}

Results: In both studies, no changes in protein expression or phosphorylation for any measured protein were observed. In Study 1, FOXO3 and FOXO4 mRNA expression decreased after IMMO and REHAB compared to PRE, whereas other mRNAs remained unchanged. Interestingly, we found significant changes in expression of the putative housekeeping genes GAPDH, HADHA and S26 with immobilization in both studies.

Conclusions: In neither study, the changes in muscle mass associated with immobilization and rehabilitation were accompanied by expected changes in expression of atrophy-related genes or phosphorylation along the Akt axis. Unexpectedly, we observed significant changes in several of the so-called housekeeping genes GAPDH, HADHA and S26 with immobilization in both studies, thereby questioning the usefulness of these genes for normalization of RNA data purposes in muscle immobilization studies.

Keywords: Immobilization, Rehabilitation, Resistance training, Akt signaling, Protein supplementation

\footnotetext{
* Correspondence: anders.fabricius.nedergaard@gmail.com

${ }^{\dagger}$ Equal contributors

'Institute of Sports Medicine, Department of Orthopedic Surgery M, Bispebjerg Hospital, Copenhagen, Denmark

${ }^{2}$ Center for Healthy Aging, Faculty of Health Sciences, University of Copenhagen, Copenhagen, Denmark
}

\section{Biomed Central}

(C) 2012 Nedergaard et al; licensee BioMed Central Ltd. This is an Open Access article distributed under the terms of the Creative Commons Attribution License (http://creativecommons.org/licenses/by/2.0), which permits unrestricted use, distribution, and reproduction in any medium, provided the original work is properly cited. 


\section{Background}

Human skeletal muscle loss is a common consequence of physical inactivity, immobilization, aging and disease [1-5]. Two to three weeks of immobilization causes a loss of muscle mass of $5-10 \%$, accompanied by a decrease in strength of $10-20 \%$ [6-8], and, accordingly, individuals with injuries that require immobilization of a limb experience a rapid loss of muscle mass and strength. The recovery from such an injury can be complicated by the lag time for strength recovery and is especially true for vulnerable population groups including older and/or frail adults [9].

Effective and quick rehabilitation of muscle mass and especially strength is of key importance to the immobilized individual. Resistance exercise training and adequate nutrition elicit increased muscle mass and strength [10], and combining resistance exercise and essential amino acids plus carbohydrates enhance muscle protein synthesis to a greater degree than either stimulus alone $[10,11]$. In addition, discrepant results on the effect of amino acid supplementation on muscle loss with immobilization have been reported [12,13].

Despite the importance of appropriate recovery, the rehabilitation of muscle mass and function following immobilization is understudied $[14,15]$ and whereas the knowledge of muscle mass signaling with immobilization has increased in recent years, there is a paucity of studies on the molecular regulation of muscle mass in the rehabilitation of immobilization-induced muscle atrophy [7].

Muscle mass is regulated by the relative rates of protein synthesis and protein breakdown, and the molecular regulation of this includes the key Akt, mammalian target of rapamycin (mTOR), glycogen synthase kinase $3 \beta$ (GSK3 $\beta$ ) and Forkhead box O (FOXO) signaling pathways [16,17]. Akt is activated by insulin and insulin-like growth factor 1 (IGF-1), and the forced transgenic or pharmacologic induction of Akt in vivo or in vitro is sufficient to cause dramatic muscle hypertrophy and inhibit atrophy [18-22]. Akt affects protein synthesis by allowing assembly of a translation initiation complex through GSK3 $\beta$ and mTOR, of which mTOR activates and inhibits its downstream targets ribosomal protein S6 kinase (S6k) and eukaryotic translation initiation factor $4 \mathrm{E}$ binding protein 1 (4E-BP1), respectively. Akt also inhibits FOXO transcription factors, which consist of FOXO1, 3 and 4 in skeletal muscle. The activation of FOXO3 induces muscle loss as well as protein degradation and stimulates the transcription of the ubiquitin ligases Atrogin-1 and Muscle Ring Finger protein 1 (MURF1), which together with FOXO1 belong to a set of muscle atrophyrelated genes ("atrogenes") that are upregulated in several types of murine muscle atrophy [18,23-25].

Accordingly, to investigate the phosphorylation and expression of candidate key molecular muscle mass regulators after immobilization and subsequent rehabilitation, we performed two separate studies. First, we immobilized the lower limb for 2 weeks followed by the in-house hospital standard physiotherapy rehabilitation for another 2 weeks. The aim of the first study was to characterize the effects of the immobilization protocol and standard rehabilitation on muscle signaling and mRNA expression (Study 1). Secondly, we conducted an intervention study using the same 2 weeks immobilization protocol during which protein/carbohydrate supplementation was given. This was followed by 6 weeks of rehabilitation in the form of resistance training and continued protein/carbohydrate supplementation. The aim of the second study was to explore the effects of a resistance training and nutrient supplementation based intervention on muscle signaling and mRNA expression during the recovery from immobilization (Study 2). 6 weeks rehabilitation training was selected in order to aim for full recovery of strength and mass. A protocol of 6 weeks of resistance training rehabilitation after 2 weeks of immobilization has been used previously by others investigating the response of the thigh muscles [7].

For Study 1, we hypothesized that the 2 weeks immobilization would decrease Akt and mTOR signaling along with increased FOXO3, Atrogin-1 and MURF1 mRNA expression, reflecting the loss of muscle mass reported previously for this study [26]. Further, we hypothesized that the standard rehabilitation would be insufficient to recover signaling and mRNA expression relative to post-immobilization. For Study 2, we hypothesized (similar to Study 1) decreased Akt and mTOR signaling along with elevated FOXO3, Atrogin-1 and MURF1 transcripts after immobilization. Regarding the subsequent resistance training and protein/carbohydrate supplement based rehabilitation, we hypothesized a full recovery of mass and strength, reflected by a reversal or normalization to basal levels of signaling and mRNA expression. Of note, as Study 1 and Study 2 are separate studies; no comparisons between the two studies are made.

\section{Methods}

\section{Study 1: Subjects}

8 young men (Table 1) were recruited following online advertising and included in Study 1. As this study also investigated tendon collagen synthesis [26], which is affected by the hormones of contraceptive pills, estradiol and progesterone [27], females were excluded. Eligibility criteria were: Male, 18-30 years of age, no chronic disease, no use of medication, no injuries in the lower body and no obesity $(\mathrm{BMI}>30)$. Incidentally, all were Caucasians and most of the subjects were recreationally active students. All subjects gave, after receiving oral and written information, written, informed consent to participate in the study, in adherence to the declaration of Helsinki. 
Table 1 Subject characteristics

\begin{tabular}{llll}
\hline Attribute & Unit & Study 1 & Study 2 \\
\hline Height & $(\mathrm{cm})$ & $184 \pm 9$ & $184 \pm 7$ \\
Weight & $(\mathrm{kg})$ & $85 \pm 12$ & $84 \pm 12$ \\
Age & $($ years $)$ & $23 \pm 3$ & $24 \pm 3$ \\
BMl & $\left(\mathrm{kg}^{*} \mathrm{~m}^{-2}\right)$ & $26 \pm 3$ & $25 \pm 3$ \\
Bodyfat & $(\%)$ & $\mathrm{NR}$ & $19.9 \pm 5.5$ \\
Self-reported PAL-factor & & $\mathrm{NR}$ & $1.78 \pm 0.36$ \\
Avg. fat intake & $(\mathrm{g})$ & $\mathrm{NR}$ & $69.3 \pm 23.8$ \\
Avg. carbohydrate intake & $(\mathrm{g})$ & $\mathrm{NR}$ & $267.5 \pm 58.3$ \\
Avg. protein intake & $(\mathrm{g})$ & $\mathrm{NR}$ & $90.3 \pm 30.3$ \\
Avg. protein intake & $(\mathrm{g} / \mathrm{kg})$ & $\mathrm{NR}$ & $1.2 \pm 0.3$
\end{tabular}

Subject characteristics for Study 1 and Study 2. NR is short for "not recorded". Data are presented as means \pm SD.

The study was approved by the local Human Subject Ethics Committee of Copenhagen and Frederiksberg [(KF) 11 2006-1743].

\section{Study 1: Design}

The subjects were assigned to 2 weeks of immobilizing casting of the lower leg in the non-dominant side, followed by 2 weeks of standard physiotherapy rehabilitation (Figure 1), with the other leg serving as a control. Muscle biopsies were sampled 1 week prior to immobilization (PRE), after the 2-week immobilization period (IMMO) and following 2 weeks of rehabilitation (REHAB $(2 \mathrm{~W})$ ), and from these biopsies mRNA and protein were isolated for use in RT-qPCR and Western blots. Strength and muscle cross-sectional area (CSA) data from this study have been published previously [26].

\section{Study 1: Standard rehabilitation protocol}

Subjects in Study 1 performed 2 weeks rehabilitation as per standard in-house hospital physiotherapy recommendations at the orthopedic department at Copenhagen University Hospital at Bispebjerg. This protocol was selected in order to characterize the effects of a standard rehabilitation course. This protocol is aimed at mobilizing the joint and reactivating neuromuscular and kinesthetic skills, more so than improving tissue protein turnover or muscle metabolism and strength.

Each of the following exercises were to be performed for approximately $60 \mathrm{~s}$ daily: 1 ) slow flexing/stretching of toes, 2) while seated, lifting a cloth off the floor, gripping it with the toes, 3) while seated, slowly sliding the foot back and forth on a cloth, keeping the heel in contact with the floor, 4) while standing, lifting the toes, 5) while standing, doing calf raises, 6) while standing, doing short lunges, performed until the knee passes the toes, 7) straight knee stretching (targeting the gastrocnemius

\section{Study 1}

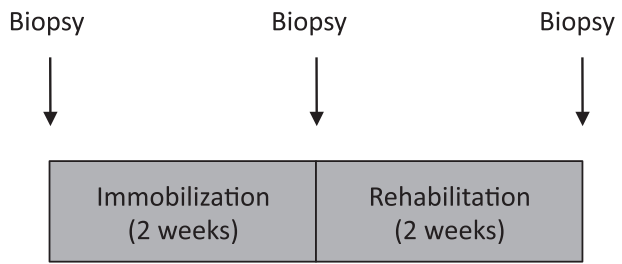

Study 2

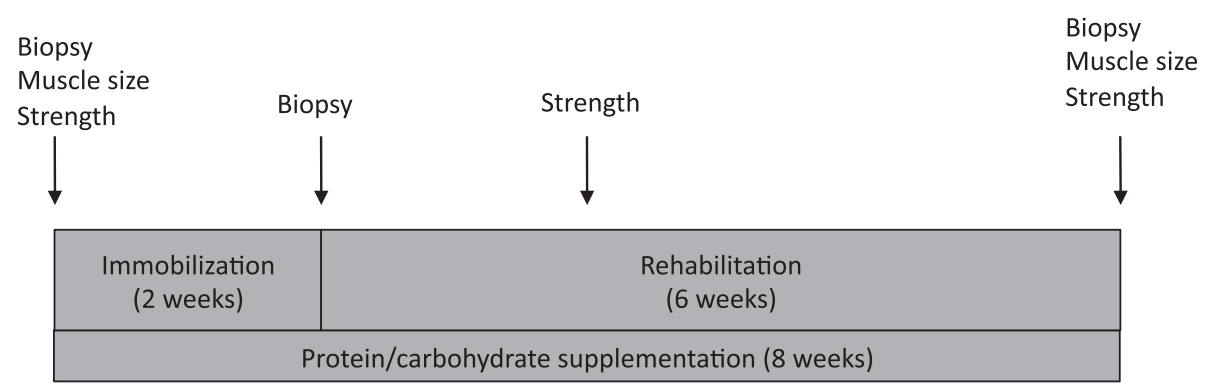

Figure 1 Study setup. Study setup and flowchart for Study 1 and 2. Muscle biopsies were only taken from the casted leg. All other measurements were bilateral from casted and control legs. 
muscle) and 8) bent-knee stretching (targeting the soleus muscle). The subjects did not maintain exercise logs.

\section{Study 2: Subjects}

In Study 2, another 8 young men (Table 1) were included from similar advertising and recruiting procedures and on the basis of similar eligibility criteria. All subjects gave, after receiving oral and written information, written consent to participate in the study, in adherence to the declaration of Helsinki. The study was approved by the local Human Subject Ethics Committee of Copenhagen and Frederiksberg [(H KF) 319605].

\section{Study 2: Design}

In Study 2, subjects were assigned to an immobilization procedure identical to that used in Study 1, but to another rehabilitation protocol comprised of resistance training for 6 weeks. Moreover, the subjects received protein/carbohydrate supplementation throughout both the immobilization and the rehabilitation period (Figure 1).

Muscle biopsies were sampled 1 week prior to immobilization (PRE), following immobilization (IMMO) and following 6 weeks of rehabilitation (REHAB (6 W)) and muscle size was measured by MRI at the same time points. Muscle strength was measured after 2 (REHAB $2 \mathrm{~W})$ and 6 (REHAB $(6 \mathrm{~W})$ weeks of rehabilitation and muscle CSA was measured at the REHAB (6 W) time point as well. Muscle strength and size data from the PRE and IMMO time points in this study have been reported elsewhere [28]. Muscle strength and size were measured as described previously $[28,29]$ Briefly, strength was maximal voluntary (isometric) plantarflexion strength with extended knee exerted against a plate connected to a strain gauge, while muscle CSA was measured from MR slice scans $10 \mathrm{~cm}$ distal to the caput fibula.

\section{Study 2: Rehabilitation exercise protocol}

Subjects in Study 2 performed resistance training directed at increasing strength, muscular endurance and increase connective tissue protein turnover [26] three times a week. During weeks 1 and 2, subjects performed $2 \times 15$ (set $\mathrm{x}$ repetitions) single-legged standing toe raises at bodyweight with full range of motion and $2 \times 15$ toe presses in a seated leg press machine at 15-20 repetition maximum (RM). During weeks 3 and 4, subjects performed $3 \times 15$ single-legged standing toe raises with additional $10 \%$ bodyweight added and 3x15 eccentric toe presses with progressive weight increases (using both legs in the concentric phase, but only one in the eccentric). During weeks 5 and 6, subjects performed the same number of set and repetitions, but with $20 \%$ bodyweight added for toe raises. The training was done supervised in-house at the hospital gym and subjects maintained exercise logs that were validated by instructors.

\section{Study 2: Protein and carbohydrate supplement protocol} Prior to immobilization and during the rehabilitation period, subjects in Study 2 maintained food logs for 3 days, which were used to calculate average habitual nutrient and protein intakes (Table 1).

During the full study (immobilization and rehabilitation), all subjects were instructed to ingest a protein and carbohydrate supplement ( $20 \mathrm{~g}$ of protein and $25 \mathrm{~g}$ of dextrose) twice daily and always after exercise. Ingestion of the protein and carbohydrate supplement was monitored only following workouts. The supplement represented a daily addition to protein and energy consumption of 44 and $16 \%$, respectively or an increase in protein consumption of $0.5 \pm 0.1 \mathrm{~g}^{*} \mathrm{~kg}^{-1 *} \mathrm{day}^{-1}$. Protein/carbohydrate supplementation began on the first day of immobilization and was continued until the last testing session.

The subjects were administered milk protein: 4 were given whey protein (Lacprodan Whey protein isolate, Arla), and 4 were given alpha-lactalbumin (Lacprodan Alpha-10, Arla; a whey subfraction protein), but as statistical endpoint analysis yielded no difference between these protein supplements at any time, they were pooled for all purposes. These two protein supplements have fairly similar amino acid compositions, e.g. both contain $21 \%$ branched-chain amino acids.

\section{Immobilization}

In both studies, the ankle joint and lower part of the nondominant leg was immobilized in a $90^{\circ}$ angle using a cast from below the knee to the toes, leaving the Achilles tendon in a neutral position. The subjects were supplied with crutches and instructed to avoid any load-bearing on the immobilized leg. After the 2 weeks of immobilization, the cast was checked for evidence of weight-bearing (any visible damage or marks after load bearing would exclude the subject), removed, and the subjects were tested and sampled again. Following cast removal, subjects were transported in a wheelchair to the MRI facility and back to the laboratory in order to avoid supporting on the immobilized leg prior to muscle biopsy sampling.

\section{Muscle biopsy sampling}

In both studies, biopsies were sampled from the medial gastrocnemius muscle, using the percutaneous Bergström needle technique [30]. Biopsies were obtained only from the casted leg and not the control leg. Before taking the biopsies, ultrasound imaging was used to identify areas of the muscle with large vessels that should be avoided during the sampling, to prevent unnecessary intramuscular hematomas. Individual biopsy sites were moved 2-3 cm between repeated samplings. In both studies, subjects were sampled at the PRE, IMMO and REHAB time point, with REHAB being after 2 weeks of rehabilitation in Study 1 and after 6 weeks in Study 2. 


\section{RNA isolation}

In both studies, approximately $10 \mathrm{mg}$ of muscle tissue was used for RNA isolation. RNA was isolated using phenol extraction [31], using the Trizol kit (Tri-Reagent, Molecular Research). The isolation was performed essentially as proposed, but with two subsequent ethanol precipitation steps, rather than one. The tissue homogenization step was performed using a bead beater (Fastprep-24, MP Biomedicals) shaking specimens in $1 \mathrm{ml}$ Trizol in a $2 \mathrm{ml}$ Biospec tube with 5 stainless steel beads $(2.3 \mathrm{~mm})$ and 5 silicon carbide grains for $15 \mathrm{~s}$ at speed 4.0 twice. Between shakings samples rested in an ice-water bath. RNA integrity was measured by electrophoresis, running 200 nanograms of RNA on a denaturing agarose gel and visualized with SYBR Green II staining.

\section{Realtime RT-qPCR}

In both studies, the mRNA expression of FOXO4 and the atrophy-related genes FOXO1, FOXO3, Atrogin-1 and MURF1 [23,25] was analyzed by real-time RT-qPCR. Total RNA (500 ng) was converted into cDNA in $20 \mu \mathrm{l}$ using the OmniScript reverse transcriptase kit (Qiagen, CA, USA) and poly-dT according to the manufacturer's protocol. For each target, $0.25 \mu \mathrm{l}$ cDNA was amplified in a $25 \mu \mathrm{l}$ SYBR Green PCR reaction containing $1 \mathrm{X}$ Quantitect SYBR Green Master Mix (Qiagen) and $100 \mathrm{nM}$ of each primer (Table 2). The amplification was monitored real-time using the MX3000P real-time PCR machine (Stratagene). The threshold cycle $(\mathrm{Ct})$ values were related to a standard curve made with the cloned PCR products and specificity ensured by melting curve analyses.

In the initial PCR assay we measured Glyceraldehyde 3phosphate dehydogenase (GAPDH) and Ribosomal protein, large, P0 (RPLP0) expression for normalization purposes, but as their expression changed in relation to each other, we proceeded to measure more putative housekeeping genes (26S, $\beta 2$-microglobulin, Cyclophillin A and HADHA) in another assay. Therefore, we measured expression of six putatively stably expressed "housekeeping" genes GAPDH, RPLP0, $\beta 2$-microglobulin ( $\beta 2 \mathrm{MG})$, Cyclophillin A, hydroxyacyl-coenzyme A dehydrogenase alpha subunit (HADHA) and ribosomal protein S26 (S26) and did indeed find significant variation within these supposedly stably expressed genes (See Results section). Thus, we proceeded to use the "GeNorm" algorithm (VBA applet for Excel) [32] to identify the housekeeping genes most stably expressed. The GeNorm housekeeping gene analysis revealed the most variable genes to be GAPDH, S26 and HADHA in descending order of variability. Including B2MG, RPLP0 and Cyclophillin A in the geometric mean used for normalization yielded a variability score of 0.151 , complying with the "stability threshold" score of 0.150 recommended in Vandesompele et al. [32]. We proceeded to generate geometric means of the
Table 2 Antibody and primer specifications

\begin{tabular}{llll}
\hline Primary Antibodies & & & \\
\hline Epitope & Manufacturer & Catalog no. & Dilution \\
Akt & Cell Signaling & 2920 & $1: 2,000$ \\
p-Akt (T308) & Cell Signaling & 2965 & $1: 2,000$ \\
p-Akt (S473) & Cell Signaling & 4060 & $1: 2,000$ \\
mTOR & Cell Signaling & 2983 & $1: 2,000$ \\
p-mTOR (S2448) & Cell Signaling & 2971 & $1: 2,000$ \\
p-mTOR (S2481) & Cell Signaling & 2974 & $1: 2,000$ \\
S6K & Cell Signaling & 9202 & $1: 2,000$ \\
p-S6K (T389) & Cell Signaling & 9206 & $1: 2,000$ \\
GSK3 $\beta$ & Abcam & Ab31826 & $1: 2,000$ \\
P-GSK3 (S9) & Cell Signaling & 9336 & $1: 2,000$ \\
4E-BP1 & Santa Cruz & Sc-81149 & $1: 200$ \\
p-4E-BP1 (T37/46) & Cell Signaling & 2855 & $1: 2,000$ \\
MURF1 & Abcam & Ab4125 & $1: 2,000$ \\
Secondary antibodies & & & \\
Epitope & Fluorophore Manufacturer & Catalog no. & Dilution \\
& conjugate & & \\
Mouse Ig & Alexa 680 Invitrogen & A21057 & $1: 10,000$ \\
Goat Ig & Alexa 680 Invitrogen & A21084 & $1: 10,000$ \\
Rabbit Ig & Dylight 800 Pierce & 35571 & $1: 10,000$ \\
PCR & & &
\end{tabular}

\section{PCR primers}

\begin{tabular}{lll} 
Target & Primers & \\
FOXO1 & Sense & GCCCAACCAAAGCTTCCCACAC \\
& Antisense & TGGACTGCTTCTCTCAGTTCCTGCT \\
FOXO3 & Sense & GCTGGGTGCCAGGCTGAAGG \\
& Antisense & TTGGCAAAGGGTITCTCTGTAGGT \\
FOXO4 & Sense & GATGAGGGCGAGGGACTGGA \\
& Antisense & TCCACATCTGAAGCAGGGGACA \\
MURF1 & Sense & TGGGGGAGCCACCTTCCTCT \\
& Antisense & ATGTTCTCAAAGCCCTGCTCTGTCT \\
Atrogin-1 & Sense & TGTACCCAAGGAAAGAGCAGTATGGA \\
& Antisense & ACGGAGCAGCTCTCTGGGTATTG \\
HADHA & Sense & GCGAGTCTGAAGCTGCCTCCTAA \\
& Antisense & GGCACATGACTGCCTCATTCACA \\
S26 & Sense & AACACCCCCACCCCGATTAGAC \\
& Antisense & GAACTCAGCTCCTTACATGGGCTT \\
Cyclophillin & Sense & TGCAGACAAGGTCCCAAAGACAG \\
& Antisense & TGAAAGCAGGAACCCTATAACCA \\
B2-microglobulin & Sense & GCTGTGCTCGCGCTACTCTCTCT \\
& Antisense & TCTGCTGGATGACGTGAGTAAACCT \\
GAPDH & Sense & CCTCCTGCACCACCAACTGCTT \\
& Antisense & GAGGGGCCATCCACAGTCTTCT \\
\hline
\end{tabular}

Specification of antibodies used for Western blots and primers used for $\mathrm{QPCR}$. 
expression of these genes and used the resulting figure for normalization. Statistics were done on normalized and log-transformed numbers. Finally, we back-transformed means and SEM's for reporting and graphical visualization.

\section{Protein isolation}

Approximately $10 \mathrm{mg}$ of muscle tissue was homogenized as described for RNA isolation, but performed in $200 \mu \mathrm{l}$ homogenization buffer $(50 \mathrm{mM}$ Tris- $\mathrm{HCl}, 1 \mathrm{mM}$ EDTA, $1 \mathrm{mM}$ EGTA, $10 \mathrm{mM} \beta$-glycerophosphate. $50 \mathrm{mM} \mathrm{NaF}$, $0.5 \mathrm{mM}$ sodium orthovanadate, $0.1 \%$ 2-mercaptoethanol, $0.1 \%$ Triton-X and protease inhibitor (Complete, Roche), adjusted to $\mathrm{pH}$ 7.5). Following bead beating, samples were briefly spun down and aliquots of the resulting supernatant were used for protein concentration determination, using the EZQ protein quantitation kit (Molecular Probes) and CCD camera (Kodak Image Station 3000MMpro). Prior to loading, aliquots of the samples were diluted to a final concentration of $1 \mathrm{ug} / \mathrm{ul}$, using $4 \mathrm{X}$ Laemmli buffer, to a final concentration of $1 \mathrm{X}$ Laemmli.

\section{Western blots}

In both studies, we measured total protein and phosphorylation for Akt (T308 and S473), mTOR (S2448 and S2481), S6k (T389), 4EBP1 (T37/46) and GSK3ß (S9) as well as protein expression of ubiquitin and MURF1 (Table 2). Western blotting was performed essentially as previously described [33]. For electrophoresis, $20 \mu \mathrm{g}$ protein per well was loaded on Criterion 4-12\% gradient gels (Bio-Rad) and run at $200 \mathrm{~V}$ for $1 \mathrm{~h}$. The gels were cut into pieces corresponding to target sizes. Gel slabs containing proteins larger than $110 \mathrm{kDa}$ were blotted in absence of methanol, while the remaining gel pieces were blotted in the presence of methanol. Gels were blotted (Trans-blot cell, Bio-Rad, $400 \mathrm{~mA}, 2 \mathrm{~h}$ ) to polyvinylidene difluoride membranes (Amersham Hybond LFP, GE Healthcare) in transfer buffer (50 mM Trisbase, $383 \mathrm{mM}$ glycine, $20 \% \mathrm{v} / \mathrm{v}$ methanol), washed briefly in distilled water and blocked for $30 \mathrm{~min}$ in 10\% Odyssey Blocking buffer in phosphate-buffered saline (PBS). Following blocking, membranes were washed in Tris-buffered saline with Tween-20 (TBST) $(50 \mathrm{mM} \mathrm{pH}$ 7.4 Tris, $150 \mathrm{mM} \mathrm{NaCl}, 0.1 \%$ Tween-20, $\mathrm{pH}$ 7.4) and incubated with primary antibodies (Table 2) overnight. Following primary antibody incubation, membranes were washed in TBST and incubated with appropriate secondary antibodies conjugated to Dylight 800 or Alexa 680 fluorophores (Table 2). For visualization, blots were scanned using an Odyssey scanner (LiCor) at $84 \mu \mathrm{m}$ resolution and standard settings and quantified using ImageJ (National Institutes of Health, USA). Where appropriate, total and phospho-antibodies were incubated simultaneously on the same membrane, each in its own wavelength channel. Prior to statistical analysis, results were normalized to individual PRE values and logtransformed. Finally, we back-transformed means and SEM's for reporting and graphical visualization.

\section{Statistics}

No statistical comparisons were made between Study 1 and 2, as we consider them separate studies. Statistical analysis was, however, performed in an identical manner between the two studies.

For Study 2 only, muscle size (CSA) and strength (MVC) PRE-normalized data were subjected to repeated measures one-way ANOVA (and post hoc testing) individually for each leg.

Western blot and RT-qPCR data were normalized as described in their respective paragraphs and logtransformed prior to being subjected to repeated measures one-way ANOVA (and post hoc testing). The log-transformation was used to ensure that the data approached normal distribution as closely as possible.

In figures, all data are presented as means \pm SEM (for RTqPCR and Western blot data back-transformed means \pm SEM). In Table 1, data are presented as means \pm SD. CSA, MVC and mRNA analyses were done using Sigmastat 3.5.0.54 (Systat Software, 2006) with Student-NewmanKeuls correction for multiple testing, whereas protein data were analyzed using SAS 9.1.3 (SAS Institute 2008). For all post hoc tests we applied a significance threshold of 0.05 .

\section{Results \\ Study 1 \\ mRNA expression}

As for mRNA (Figure 2A), we observed significant time effects for FOXO3 $(p=0.004)$, FOXO4 $(p=0.013)$, GAPDH $(p=0.005)$, HADHA $(p=0.010)$ and S26 $(p=0.037)$ transcripts. For FOXO3 and FOXO4 this was manifested in the form of a downregulation at the IMMO time point $(-40 \%$ for FOXO3 $(p=0.006)$ and $-58 \%$ for FOXO4 $(p=0.026))$ that persisted until the REHAB (2 W) time point $(-19 \%$ for FOXO3 $(p=0.006)$ and $-35 \%$ for FOXO4 $(p=0.009))$. GAPDH and HADHA were also downregulated at the IMMO time point $(-53 \%$ for GAPDH $(p=0.004)$ and $-40 \%$ for HADHA $(p=0.008)$ ), but returned almost back to baseline expression at the REHAB time point. Despite manifesting a time effect, S26 was not significantly downregulated at either time point (Figure 2A).

\section{Protein expression and phosphorylation}

Despite the obvious changes in muscle mass [26], we observed no significant modulation of total or phosphoprotein levels of Akt, GSK3 $\beta$, 4EBP1, ubiquitin or MURF1 in Study 1 (Figure 2B). Total and phosphorylated levels of mTOR and S6k were below the detection threshold. 


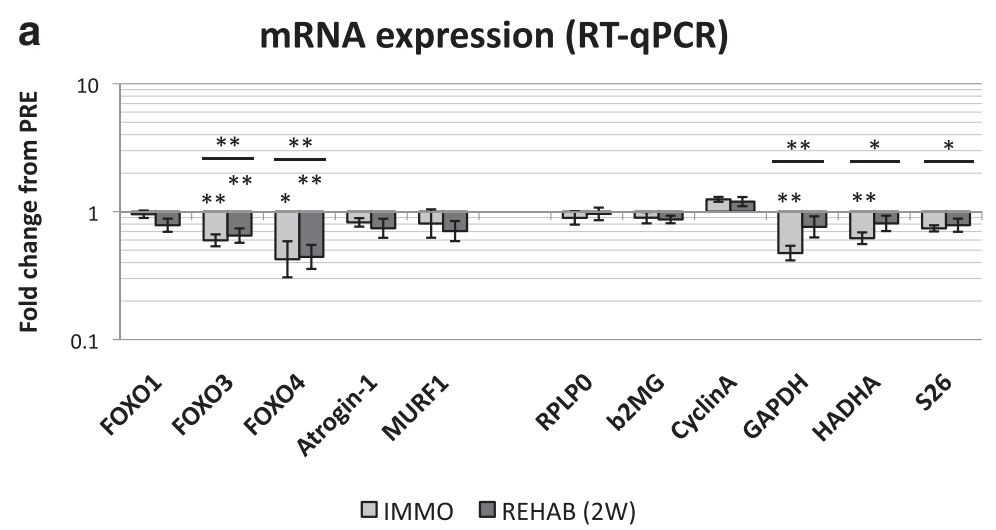

b Protein expression/phosphorylation

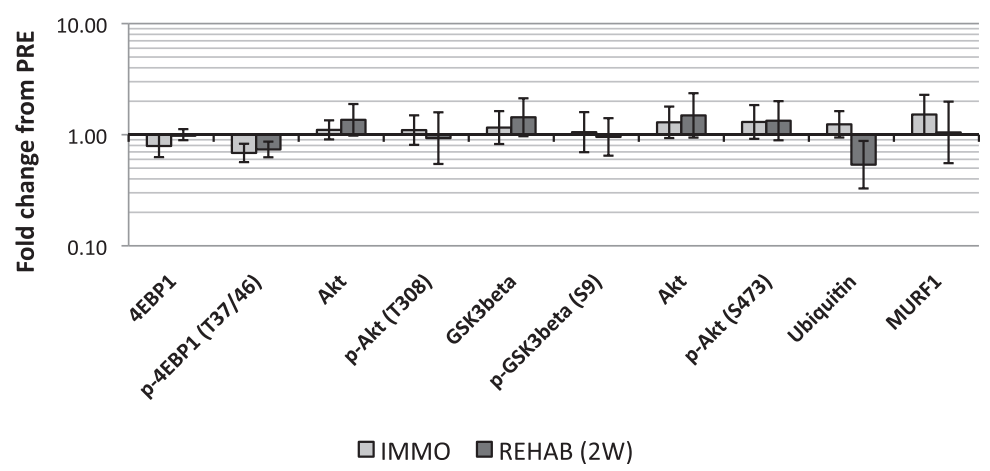

Figure 2 Data for Study 1. A: mRNA expression measured by RT-qPCR. mRNA data are normalized to geometric means of Cyclophillin A, $\beta 2-$ microglobulin and RPLPO and are relative to individual PRE values. Target genes are presented in the left side panel, whereas putative housekeeping genes are presented in the right side panel. Data are presented as back-transformed mean \pm SEM. Light gray columns represent IMMO and dark gray REHAB. B: Total protein and protein phosphorylation measured by Western blot, relative to individual PRE values. Data are presented as back-transformed mean \pm SEM. Total Akt is represented twice as it was measured along with each phospho-Akt. Light gray columns represent IMMO and dark gray REHAB. * denotes a difference from PRE with $0.05>p \geq 0.01$. ** denotes a difference from PRE with $0.01>p \geq 0.001$. Underscored asterisks denote main (time) effects.

\section{Study 2}

\section{Muscle strength and size}

In Study 2, we report additional muscle strength and size data for the REHAB time points. For strength, no significant time effects were detected in either leg. Following 2 and 6 weeks of rehabilitation, strength was elevated to levels slightly higher than those recorded before immobilization, but these differences did not reach significance. For muscle size, no differences were observed between the REHAB (6 W) time point and PRE.

\section{mRNA expression}

For mRNA (Figure 3A), we observed time effects for FOXO1 $(p=0.030), \quad$ Atrogin-1 $(p=0.046), \quad$ GAPDH $(p=0.001)$, HADHA $(p=0.035)$ and S26 $(p=0.001)$. Notably, for neither FOXO1 nor Atrogin-1, the main effect could be observed as deviations from PRE. For both GAPDH and HADHA, we observed a downregulation at the IMMO time point $(-39 \%$ for GAPDH $(p=0.001)$ and $-24 \%$ for HADHA $(p=0.043))$ and a subsequent return to baseline expression, whereas for S26 we found a downregulation at the IMMO time point that persisted throughout the REHAB (6 W) time point $(-26 \%$ at IMMO $(p=0.002)$ and $-20 \%$ at REHAB $(p=0.006)$ (Figure 3A).

\section{Protein expression and phosphorylation}

Contrary to the changes in muscle mass reported previously [28], we found no significant modulation of total or phosphoprotein levels of Akt, GSK3 $\beta$, 4EBP1, ubiquitin or MURF1 in Study 2 (Figure 3B). Total and phosphorylated levels of mTOR and S6k were below the detection threshold. 

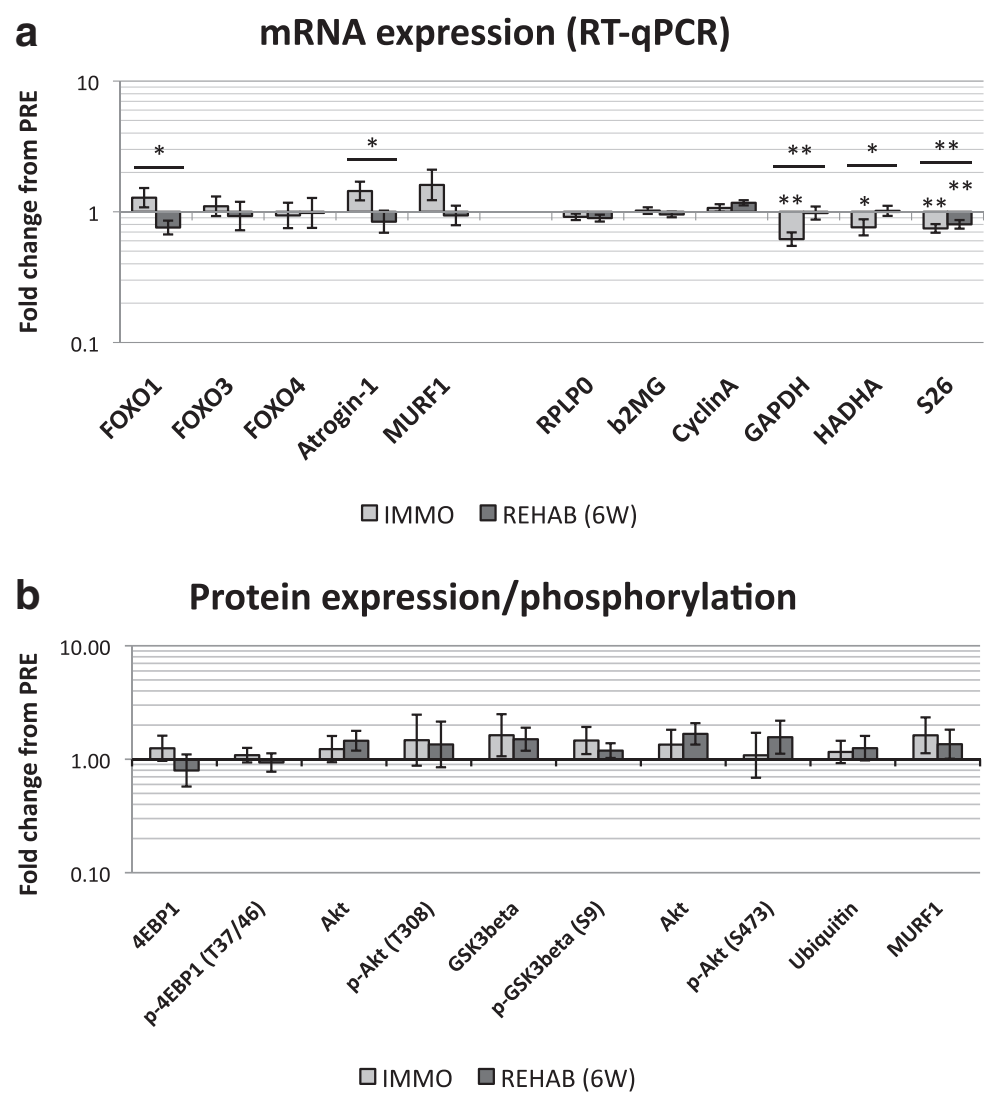

Figure 3 Data for Study 2. A: mRNA expression measured by RT-qPCR. mRNA data are normalized to geometric means of Cyclophillin A, B2microglobulin and RPLPO and are relative to individual PRE values. Target genes are presented in the left side panel, whereas putative housekeeping genes are presented in the right side panel. Data are presented as back-transformed mean \pm SEM. Light gray columns represent IMMO and dark gray REHAB. B: Total protein and protein phosphorylation measured by Western blot, relative to individual PRE values. Data are presented as back-transformed mean \pm SEM. Total Akt is represented twice as it was measured along with each phospho-Akt. Light gray columns represent IMMO and dark gray REHAB. ${ }^{*}$ denotes a difference from PRE with $0.05>p \geq 0.01$. ${ }^{* *}$ denotes a difference from PRE with $0.01>p \geq 0.001$. Underscored asterisks denote main (time) effects.

\section{Discussion}

For Study 1, we hypothesized that the 2 weeks immobilization would decrease Akt and mTOR signaling along with increased FOXO3, Atrogin-1 and MURF1 mRNA expression, reflecting the loss of muscle mass previously reported for this study [26]. We observed no changes in Akt and mTOR signaling, and of FOXO3, Atrogin-1 and MURF1 only FOXO3 was significantly downregulated after immobilization, which is opposite of what we expected. Furthermore, we hypothesized that the standard rehabilitation would be insufficient to recover signaling and mRNA expression relative to post-immobilization. As hypothesized, signaling and all mRNAs, except the downregulated FOXO3, were unchanged with rehabilitation relative to the IMMO time point.

For Study 2, we hypothesized (similar to study 1) decreased Akt and mTOR signaling along with elevated
FOXO3, Atrogin-1 and MURF1 transcripts after immobilization. Unexpectedly, Akt and mTOR signaling and the measured mRNAs remained unchanged after immobilization. Regarding the subsequent combined resistance training and protein/carbohydrate supplementation based rehabilitation, we hypothesized a full recovery of mass and strength, reflected by a reversal or normalization to basal levels of signaling and mRNA expression. Indeed, this rehabilitation protocol restored both mass and strength, whereas signaling and mRNA expression remained unchanged after rehabilitation relative to post-immobilization.

\section{Protein expression and phosphorylation}

To our knowledge, we present the first results on Akt, 4E-BP1 and GSK3 $\beta$ phosphorylation following rehabilitation after immobilization, and, unexpectedly, we show 
no changes. Contrary to our hypothesis for both Study 1 and Study 2, the total and phosphorylation levels of the measured proteins remained unchanged after 2 weeks immobilization. This is similar to a previous human 10 days immobilization study reporting unchanged total and phosphorylated levels of Akt, S6k and 4E-BP1 [6], although a decrease in Akt S473 phosphorylation after 20 days immobilization has been observed as well [34]. Of note, these studies $[6,34]$ were performed on vastus lateralis muscle, whereas our data is generated from gastrocnemius muscle, which may affect the response. Moreover, the high variation in the data may explain, at least partly, the absence of significant differences with time or treatment (Figures 2B and 3B). Due to this variation we cannot exclude the possibility that some minor modulation occurs, but it is unlikely that the observed variation masks large changes in phosphorylation status.

\section{mRNA expression}

Unexpectedly, we observed a significant decrease in $\mathrm{FOXO} 3$ and FOXO4 mRNA expression with immobilization as well as rehabilitation in Study 1 (Figure 2A). This could be interpreted as an anti-catabolic response, but given that the subjects were atrophic at the IMMO time point [26] and anabolic at the REHAB time point, this represent a discrepancy between the suggested gene function and the physiological condition. We cannot rule out the possibility that this response is secondary to other regulation events and thus not part of a primary response. It is still a matter of debate what the individual biological contributions of each FOXO gene are and under what circumstances they are activated, but murine in vitro and in vivo studies indicate that the FOXO genes should be considered negative regulators of muscle mass [20,35-37].

FOXO transcript behavior in vivo is poorly characterized with immobilization and our data represent novel findings on the effects of immobilization and rehabilitation on FOXO transcript regulation in human muscle. Regarding the sparse literature that does exist, FOXO3 reporter activity has been shown to be upregulated with immobilization in an animal model [38], whereas in a human model, 3 and 20 days of unloading produced no changes in FOXO1 or FOXO3 mRNA and protein expression levels [34,39].

As for the "atrogenes" Atrogin-1 and MURF1 [18,23], in Study 2, we observed a tendency $(p=0.10)$ towards an increase from PRE in Atrogin-1 expression (Figure 3A) after immobilization. Both Atrogin-1 and MURF1 have previously been shown to be upregulated in a 14-day human immobilization study [7], although in that study, the upregulation of MURF1 did not reach statistical significance. Other time course studies show that Atrogin-1 and/or MURF1 expression increases in the initial phase of immobilization and gradually declines, sometimes even to levels below baseline $[6,40]$. Also, in the study by Jones et al. [7], Atrogin-1 and MURF1 seem to return to pre-levels with rehabilitation like in the present study, but with an apparent "undershoot", a finding we cannot replicate due to our less detailed time course.

\section{Normalization of mRNA expression}

In the initial PCR assay we measured GAPDH and RPLPO expression for normalization purposes, but as their expression changed in relation to each other, we proceeded to measure more putative housekeeping genes (26S, $\beta 2$ microglobulin, Cyclophillin A and HADHA) in another assay. Actually, we have previously shown that our most frequently used normalization genes RPLP0 and GAPDH change in rats with hindlimb unloading, relative to muscle weight as well as relative to total RNA [41]. Accordingly, we used the method suggested by Vandesompele et al. [32] to determine which genes were the most stably expressed and used those for normalization. This analysis indicated GAPDH, HADHA and S26 to be the most variable of the measured housekeeping genes. Indeed, in both of our immobilization experiments, all of these genes displayed decreases in expression with immobilization, with GAPDH actually returning to baseline levels after rehabilitation (Figures $2 \mathrm{~A}$ and $3 \mathrm{~A}$ ), thereby making these genes highly unsuitable for normalization purposes in immobilization studies. This is particularly relevant for GAPDH, being one of the most common normalization genes used and due to it responding drastically to immobilization, thereby not being fit for normalization purposes. This may have implications for interpretation of existing immobilization studies using GAPDH as an internal reference in RT-qPCR analyses without further validation of housekeeping gene expression stability [42-44], and should most certainly be kept in mind in future immobilization studies measuring mRNA expression.

\section{Limitations}

The discontinuous nature of these studies represents a major limitation. The missing time points and discrepant time courses do not allow for interstudy comparison, which would otherwise have been informative. Moreover, using the contralateral limb as a control in immobilization studies is controversial as the contralateral limb may experience a compensatory training effect due to increased stress [45]. This is especially true when combined with protein/carbohydrate supplementation as this is thought to contribute to hypertrophy only in conjunction with exercise or increased workload [46]. Therefore, the contralateral leg cannot be considered a true, passive control within this study.

The variation in our Western blots was higher than expected; part of this can likely be ascribed to keeping our stock samples in a native buffer. Since then, we have 
found that denaturing samples immediately following sample homogenization yields more consistent results.

In Study 1, no exercise logs were maintained, and this could mask low compliance, which in turn could cause impaired rehabilitation efficiency. Moreover, it must be noted that the ingestion of supplements were only supervised on post-workout occasions, allowing for compliance issues.

\section{Conclusions}

In Study 2, we observed full strength recovery after 2 weeks of rehabilitation. In both studies, no changes in protein expression or phosphorylation for any measured protein were observed. In Study 1, FOXO3 and FOXO4 mRNA expression decreased after IMMO and REHAB compared to PRE, whereas other mRNAs remained unchanged. Interestingly, we found significant changes in expression of the putative housekeeping genes GAPDH, HADHA and S26 with immobilization in both studies.

Accordingly, in either study, changes in muscle mass after immobilization and subsequent rehabilitation were not reflected in total protein or phosphorylation status of Akt and mTOR pathway components. The changes in the so-called housekeeping genes GAPDH, HADHA and S26 with immobilization in both studies question the usefulness of these genes for normalization purposes in muscle immobilization studies, and a more thorough characterization of changes in housekeeping genes is of relevance to future immobilization studies.

In perspective, this calls for further research, preferably a full randomized controlled trial, comparing the contributions of protein/carbohydrate supplementation and resistance training, individually as well as in combination, on immobilization-induced atrophy and rehabilitationinduced hypertrophy and related molecular regulation.

\section{Competing interests}

The authors declare that they have no competing interests.

\section{Acknowledgements}

This work was supported by the Danish National Research Board, The Novo Nordisk Foundation, The Lundbeck Foundation, the Danish Rheumatism Association and the Nordea Foundation.

\section{Authors' contributions}

AN contributed to biopsy sampling, RNA and protein isolation, RT-qPCR and Western blot analyses, statistics, data analysis and interpretation, and manuscript writing. JGJ contributed to biopsy sampling, RNA and protein isolation, RT-qPCR, Western blotting, data interpretation and manuscript writing. JP contributed to study design, recruiting and training in Study 2 and part of Study 1 as well as strength and muscle CSA measurements. BC contributed to study design, recruiting and training in Study 1 as well as strength and CSA measurements. NS contributed to RNA isolation and mRNA quantification. HL contributed to study concept and design, organizing and funding both trials. MK contributed to study concept, design and funding and to manuscript writing. PS was providing technical support and guidance for laboratory work, contributed to data analysis, statistics and interpretation and contributed to manuscript writing. All authors read and approved the final manuscript.
Received: 18 July 2011 Accepted: 28 March 2012

Published: 28 March 2012

\section{References}

1. Olsen RH, Krogh-Madsen R, Thomsen C, Booth FW, Pedersen BK: Metabolic responses to reduced daily steps in healthy nonexercising men. JAMA 2008, 299:1261-1263.

2. Jespersen JG, Nedergaard A, Andersen LL, Schjerling P, Andersen JL: Myostatin expression during human muscle hypertrophy and subsequent atrophy: increased myostatin with detraining. Scand J Med Sci Sports 2011, 21:215-23

3. Phillips SM, Glover El, Rennie MJ: Alterations of protein turnover underlying disuse atrophy in human skeletal muscle. J Appl Physiol 2009, 107:645-654.

4. Baumgartner RN, Koehler KM, Gallagher D, Romero L, Heymsfield SB, Ross RR, Garry PJ, Lindeman RD: Epidemiology of sarcopenia among the elderly in New Mexico. Am J Epidemiol 1998, 147:755-763.

5. Evans WJ, Morley JE, Argiles J, Bales C, Baracos V, Guttridge D, Jatoi A, Kalantar-Zadeh K, Lochs H, Mantovani G, et al: Cachexia: a new definition. Clin Nutr 2008, 27:793-799.

6. de Boer MD, Selby A, Atherton P, Smith K, Seynnes OR, Maganaris CN, Maffulli N, Movin T, Narici MV, Rennie MJ: The temporal responses of protein synthesis, gene expression and cell signalling in human quadriceps muscle and patellar tendon to disuse. J Physio/ 2007, 585:241-251.

7. Jones SW, Hill RJ, Krasney PA, O'Conner B, Peirce N, Greenhaff PL: Disuse atrophy and exercise rehabilitation in humans profoundly affects the expression of genes associated with the regulation of skeletal muscle mass. FASEB J 2004, 18:1025-1027.

8. Glover El, Phillips SM, Oates BR, Tang JE, Tarnopolsky MA, Selby A, Smith K, Rennie MJ: Immobilization induces anabolic resistance in human myofibrillar protein synthesis with low and high dose amino acid infusion. J Physiol 2008, 586:6049-6061.

9. Hvid L, Aagaard P, Justesen L, Bayer ML, Andersen JL, Ortenblad N, Kjaer M, Suetta C: Effects of aging on muscle mechanical function and muscle fiber morphology during short-term immobilization and subsequent retraining. J Appl Physio/ 2010, 109:1628-1634.

10. Dreyer HC, Drummond MJ, Pennings B, Fujita S, Glynn EL, Chinkes DL, Dhanani S, Volpi E, Rasmussen BB: Leucine-enriched essential amino acid and carbohydrate ingestion following resistance exercise enhances mTOR signaling and protein synthesis in human muscle. Am J Physiol Endocrinol Metab 2008, 294:E392-E400.

11. Fujita S, Dreyer HC, Drummond MJ, Glynn EL, Cadenas JG, Yoshizawa F, Volpi E, Rasmussen BB: Nutrient signalling in the regulation of human muscle protein synthesis. J Physiol 2007, 582:813-823.

12. Paddon-Jones D, Sheffield-Moore M, Urban RJ, Sanford AP, Aarsland A, Wolfe RR, Ferrando AA: Essential amino acid and carbohydrate supplementation ameliorates muscle protein loss in humans during 28 days bedrest. J Clin Endocrinol Metab 2004, 89:4351-4358.

13. Trappe TA, Burd NA, Louis ES, Lee GA, Trappe SW: Influence of concurrent exercise or nutrition countermeasures on thigh and calf muscle size and function during 60 days of bed rest in women. Acta Physiol (Oxf) 2007, 191:147-159.

14. Marimuthu K, Murton AJ, Greenhaff PL: Mechanisms regulating muscle mass during disuse atrophy and rehabilitation in humans. J App/ Physiol 2011, 110:555-560

15. Murton AJ, Greenhaff PL: Physiological control of muscle mass in humans during resistance exercise, disuse and rehabilitation. Curr Opin Clin Nutr Metab Care 2010, 13:249-254.

16. Sandri M: Signaling in muscle atrophy and hypertrophy. Physiology (Bethesda) 2008, 23:160-170.

17. Ruegg MA, Glass DJ: Molecular mechanisms and treatment options for muscle wasting diseases. Annu Rev Pharmacol Toxicol 2011, 51:373-395.

18. Bodine SC, Latres E, Baumhueter S, Lai VK, Nunez L, Clarke BA, Poueymirou WT, Panaro FJ, Na E, Dharmarajan K, et al: Identification of ubiquitin ligases required for skeletal muscle atrophy. Science 2001, 294:1704-1708.

19. Bodine SC, Stitt TN, Gonzalez M, Kline WO, Stover GL, Bauerlein R, Zlotchenko E, Scrimgeour A, Lawrence JC, Glass DJ, Yancopoulos GD: Akt/ mTOR pathway is a crucial regulator of skeletal muscle hypertrophy and can prevent muscle atrophy in vivo. Nat Cell Biol 2001, 3:1014-1019.

20. Zhao J, Brault JJ, Schild A, Cao P, Sandri M, Schiaffino S, Lecker SH, Goldberg $\mathrm{AL}$ : FoxO3 coordinately activates protein degradation by the autophagic/ 
lysosomal and proteasomal pathways in atrophying muscle cells. Cell Metab 2007, 6:472-483.

21. Rommel C, Bodine SC, Clarke BA, Rossman R, Nunez L, Stitt TN, Yancopoulos GD, Glass DJ: Mediation of IGF-1-induced skeletal myotube hypertrophy by $\mathrm{PI}(3) \mathrm{K} / \mathrm{Akt} / \mathrm{mTOR}$ and $\mathrm{PI}(3) \mathrm{K} / \mathrm{Akt} / \mathrm{GSK} 3$ pathways. Nat Cell Biol 2001, 3:1009-1013.

22. Lai KM, Gonzalez M, Poueymirou WT, Kline WO, Na E, Zlotchenko E, Stitt TN, Economides AN, Yancopoulos GD, Glass DJ: Conditional activation of akt in adult skeletal muscle induces rapid hypertrophy. Mol Cell Biol 2004, 24:9295-9304

23. Sandri M, Sandri C, Gilbert A, Skurk C, Calabria E, Picard A, Walsh K, Schiaffino S, Lecker SH, Goldberg AL: Foxo transcription factors induce the atrophy-related ubiquitin ligase atrogin-1 and cause skeletal muscle atrophy. Cell 2004, 117:399-412.

24. Sacheck JM, Hyatt JP, Raffaello A, Jagoe RT, Roy RR, Edgerton VR, Lecker SH, Goldberg AL: Rapid disuse and denervation atrophy involve transcriptional changes similar to those of muscle wasting during systemic diseases. FASEB J 2007, 21:140-155.

25. Lecker SH, Jagoe RT, Gilbert A, Gomes M, Baracos V, Bailey J, Price SR, Mitch WE, Goldberg AL: Multiple types of skeletal muscle atrophy involve a common program of changes in gene expression. FASEB J 2004, 18:39-51.

26. Christensen B, Dyrberg E, Aagaard P, Kjaer M, Langberg H: Short-term immobilization and recovery affect skeletal muscle but not collagen tissue turnover in humans. J Appl Physiol 2008, 105:1845-1851.

27. Hansen M, Kongsgaard M, Holm L, Skovgaard D, Magnusson SP, Qvortrup K, Larsen JO, Aagaard P, Dahl M, Serup A, et al: Effect of estrogen on tendon collagen synthesis, tendon structural characteristics, and biomechanical properties in postmenopausal women. J Appl Physiol 2009, 106:1385-1393.

28. Pingel J, Moerch $L$, Kjaer $M$, Langberg $H$ : The influence of training status on the drop in muscle strength after acute exercise. Eur J Appl Physiol 2009, 106:605-611.

29. Magnusson SP, Aagaard P, Dyhre-Poulsen P, Kjaer M: Load-displacement properties of the human triceps surae aponeurosis in vivo. J Physio/ 2001, 531:277-288.

30. Bergstrom J: Percutaneous needle biopsy of skeletal muscle in physiological and clinical research. Scand J Clin Lab Invest 1975, 35:609-616.

31. Chomczynski P, Sacchi N: Single-step method of RNA isolation by acid guanidinium thiocyanate-phenol-chloroform extraction. Anal Biochem 1987, 162:156-159.

32. Vandesompele J, De Preter K, Pattyn F, Poppe B, Van Roy N, De Paepe A, Speleman F: Accurate normalization of real-time quantitative RT-PCR data by geometric averaging of multiple internal control genes. Genome Biol 2002, 3:RESEARCH0034

33. Jespersen JG, Nedergaard A, Reitelseder S, Mikkelsen UR, Dideriksen KJ, Agergaard J, Kreiner F, Pott FC, Schjerling P, Kjaer M: Activated protein synthesis and suppressed protein breakdown signaling in skeletal muscle of critically ill patients. PLoS One 2011, 6:e18090.

34. Sakuma K, Watanabe K, Hotta N, Koike T, Ishida K, Katayama K, Akima H: The adaptive responses in several mediators linked with hypertrophy and atrophy of skeletal muscle after lower limb unloading in humans. Acta Physiol (Oxf) 2009, 197:151-159.

35. Mammucari C, Milan G, Romanello V, Masiero E, Rudolf R, Del Piccolo P, Burden SJ, Di Lisi R, Sandri C, Zhao J, et al: FoxO3 controls autophagy in skeletal muscle in vivo. Cell Metab 2007, 6:458-471.

36. McLoughlin TJ, Smith SM, DeLong AD, Wang H, Unterman TG, Esser KA: FoxO1 induces apoptosis in skeletal myotubes in a DNA-bindingdependent manner. Am J Physiol Cell Physiol 2009, 297:C548-C555.

37. Moylan JS, Smith JD, Chambers MA, McLoughlin TJ, Reid MB: TNF induction of atrogin-1/MAFbx mRNA depends on Foxo4 expression but not AKTFoxo1/3 signaling. Am J Physiol Cell Physiol 2008, 295:C986-C993.

38. Dodd SL, Gagnon BJ, Senf SM, Hain BA, Judge AR: Ros-mediated activation of NF-kappaB and Foxo during muscle disuse. Muscle Nerve 2010, 41:110-113.

39. Gustafsson T, Osterlund T, Flanagan JN, von Walden F, Trappe TA, Linnehan RM, Tesch PA: Effects of 3 days unloading on molecular regulators of muscle size in humans. J Appl Physiol 2010, 109:721-727.

40. Abadi A, Glover El, Isfort RJ, Raha S, Safdar A, Yasuda N, Kaczor JJ, Melov S, Hubbard A, Qu X, et al: Limb immobilization induces a coordinate downregulation of mitochondrial and other metabolic pathways in men and women. PLoS One 2009, 4:e6518.

41. Heinemeier KM, Olesen JL, Haddad F, Schjerling P, Baldwin KM, Kjaer M: Effect of unloading followed by reloading on expression of collagen and related growth factors in rat tendon and muscle. J Appl Physio/ 2009 106:178-186.

42. Urso ML, Scrimgeour AG, Chen YW, Thompson PD, Clarkson PM: Analysis of human skeletal muscle after $48 \mathrm{~h}$ immobilization reveals alterations in mRNA and protein for extracellular matrix components. J Appl Physiol 2006, 101:1136-1148.

43. Wagatsuma A, Yamazaki Y, Mizuno K, Yamada S: Molecular properties and gene expression of albumin in the skeletal muscle following hindlimb immobilization in a shortened position. Acta Neuropathol 2001, 101:540-546.

44. Hortobagyi T, Dempsey L, Fraser D, Zheng D, Hamilton G, Lambert J, Dohm $L$ : Changes in muscle strength, muscle fibre size and myofibrillar gene expression after immobilization and retraining in humans. J Physio/ 2000, 524(Pt 1):293-304

45. Lu D-X, Käser L, Muntener M: Experimental changes to limb muscles elicit contralateral reactions: the problem of controls. J Exp Biol 1999, 202:1691-1700

46. Rennie MJ, Wackerhage H, Spangenburg EE, Booth FW: Control of the size of the human muscle mass. Annu Rev Physiol 2004, 66:799-828.

doi:10.1186/1756-0500-5-166

Cite this article as: Nedergaard et al: Effects of 2 weeks lower limb immobilization and two separate rehabilitation regimens on gastrocnemius muscle protein turnover signaling and normalization genes. BMC Research Notes 2012 5:166.

\section{Submit your next manuscript to BioMed Central and take full advantage of:}

- Convenient online submission

- Thorough peer review

- No space constraints or color figure charges

- Immediate publication on acceptance

- Inclusion in PubMed, CAS, Scopus and Google Scholar

- Research which is freely available for redistribution 